\title{
Dose-response effects of systemic anandamide administration in mice sequentially submitted to the open field and elevated plus-maze tests
}

\author{
A. Ribeiro, V. Ferraz-de-Paula, M.L. Pinheiro and J. Palermo-Neto \\ Laboratório de Farmacologia Aplicada e Toxicologia, Departamento de Patologia, Faculdade de Medicina \\ Veterinária e Zootecnia, Universidade de São Paulo, São Paulo, SP, Brasil \\ Correspondence to: J. Palermo-Neto, Departamento de Patologia, Faculdade de Medicina Veterinária e \\ Zootecnia, USP, Av. Prof. Dr. Orlando Marques de Paiva, 87, 05508-200 São Paulo, SP, Brasil \\ Fax: +55-11-3091-7829. E-mail: jpalermo@usp.br
}

\begin{abstract}
The endocannabinoid system is involved in the control of many physiological functions, including the control of emotional states. In rodents, previous exposure to an open field increases the anxiety-like behavior in the elevated plus-maze. Anxiolytic-like effects of pharmacological compounds that increase endocannabinoid levels have been well documented. However, these effects are more evident in animals with high anxiety levels. Several studies have described characteristic inverted U-shaped dose-response effects of drugs that modulate the endocannabinoid levels. However, there are no studies showing the effects of different doses of exogenous anandamide, an endocannabinoid, in animal models of anxiety. Thus, in the present study, we determined the dose-response effects of exogenous anandamide at doses of $0.01,0.1$, and $1.0 \mathrm{mg} / \mathrm{kg}$ in C57BL/6 mice ( $\mathrm{N}=10$ / group) sequentially submitted to the open field and elevated plus-maze. Anandamide was diluted in $0.9 \%$ saline, ethyl alcohol, Emulphor ${ }^{\circledR}(18: 1: 1)$ and administered ip $(0.1 \mathrm{~mL} / 10 \mathrm{~g}$ body weight); control animals received the same volume of anandamide vehicle. Anandamide at the dose of $0.1 \mathrm{mg} / \mathrm{kg}$ (but not of 0.01 or $1 \mathrm{mg} / \mathrm{kg}$ ) increased $(P<0.05)$ the time spent and the distance covered in the central zone of the open field, as well as the exploration of the open arms of the elevated plus-maze. Thus, exogenous anandamide, like pharmacological compounds that increase endocannabinoid levels, promoted a characteristic inverted U-shaped dose-response effect in animal models of anxiety. Furthermore, anandamide $(0.1 \mathrm{mg} / \mathrm{kg}) \mathrm{induced}$ an anxiolytic-like effect in the elevated plus-maze $(P<0.05)$ after exposing the animals to the open field test.
\end{abstract}

Key words: Endocannabinoid; Anandamide; Anxiety; Open field; Elevated plus-maze

Research supported by FAPESP (\#04/14128-0) and CNPq (\#301708/2004-5 and \#477621/2004-0).

Received September 18, 2008. Accepted March 2, 2009

\section{Introduction}

The discovery of the cannabinoid receptors (CB1- and CB2-cannabinoid receptors) and their major ligands $\mathrm{N}$ arachidonylethanolamide (anandamide) and 2-arachidonoylglycerol led to the characterization of the endocannabinoid system two decades ago (1-4). The endocannabinoid system is known to play a modulatory role in emotional states such as anxiety and fear (5).

Anandamide interacts with CB1, TRPV1 and CB2 re- ceptors (in descending order of affinity, respectively) (6). Previous studies have described anxiolytic-like effects of a low dose of exogenous anandamide in animals exposed to the open field (7), or, when injected into the dorsolateral periaqueductal gray, in the elevated plus-maze (8). A similar effect was observed after administration of URB597, an inhibitor of fatty acid amide hydrolase $(9,10)$. However, contradictory results were obtained with AM404, an inhibitor of anandamide re-uptake. In fact, while Bortolato et al. (11) described an anxiolytic-like effect in the elevated plus- 
maze regarding defensive withdrawal and separation-induced ultrasonic vocalizations, Bitencourt et al. (12) recently reported that this effect was observed in the fearpotentiated plus-maze test, but not in the traditional version of the elevated plus-maze.

The present study was designed to determine the dose $x$ response effects of exogenous anandamide administration in adult C57BL/6 male mice sequentially submitted to the open field and elevated plus-maze test. Indeed, there are no studies showing the effects of different systemically injected anandamide doses on signs indicative of anxiolytic-like behavior determined sequentially in two different models and using the same animals. Previous results from our group and others have shown that testing animals in an open field or in a hole board immediately before the elevated plus-maze test significantly elevates animal activity within this apparatus, i.e., the total number of open and closed arm entries (13), with a consequent easier analysis of the elevated plus-maze data.

\section{Material and Methods}

Forty male C57BL/6 mice from our own colony weighing 20-30 g and approximately 2 months old were used. The animals were housed in groups of 4 per cage under conditions of controlled temperature $\left(22 \pm 2^{\circ} \mathrm{C}\right)$, humidity (65-70\%), and artificial lighting (12-h light/12-h dark, lights on at 7:00 am), with free access to rodent chow and water. Sterilized and residue-free wood shavings were used as animals bedding. The experiments were performed in a different room with similar housing conditions, to which the animals were transferred and maintained in their home cages 7 days before the beginning of the experiments. Animals were housed and used in accordance with the guidelines of the Committee on Care and Use of Laboratory Animal Resources of the School of Veterinary Medicine, University of São Paulo, Brazil.

Anandamide (N-arachidonylethanolamide) was purchased from Sigma-Aldrich (USA). The compound was made up in normal saline, ethyl alcohol, and Emulphor ${ }^{\circledR}$, 18:1:1, and administered intraperitoneally (ip) at doses of $0.01,0.1$, and $1.0 \mathrm{mg} / \mathrm{kg}$ (0.1 mL/10 g weight) (7). Control animals received the same volume of anandamide vehicle. Ten minutes after treatment, the animals were first submitted to an open field test and immediately after to the elevated plus-maze test.

Both the locomotor activity in the open field and the free exploration of the elevated plus-maze apparatus were measured. As stated, the experiments were performed in sequence. To minimize the influences of possible circadian changes in open field and elevated plus-maze behav- iors, control and experimental animals were alternated for observation, being analyzed at the same time of day (between 8:00 am and 12:00 pm). The experimental devices used were washed with an alcohol-water solution (5\%) before placing the animals to obviate possible biasing effects due to odor clues left by previous animals.

The open-field apparatus was described in details elsewhere (14). Briefly, it consists of a round wooden arena (40 $\mathrm{cm}$ in diameter, 40-cm high walls) painted white and virtually divided by software (Ethovision ${ }^{\circledR}$ version 1.9; Noldus Information Technology, USA) into two zones: central (center + medium) peripheral (external + thigmotaxis). The apparatus is elevated $55 \mathrm{~cm}$ above the floor. For the observations, each mouse was placed individually in the center of the apparatus and observed for $5 \mathrm{~min}$ for total locomotor activity (distance traveled in $\mathrm{cm}$ ) and time spent (s) in locomotor activity in each of the two open field zones. A video camera mounted $100 \mathrm{~cm}$ above the arena was used to collect the data that were analyzed by an Ethovision System ${ }^{\circledR}$ software (Noldus Information Technology) installed on an IBM-compatible computer placed in an adjacent room.

The elevated plus-maze was made of wood, painted white, and had two open arms $(25 \times 5 \mathrm{~cm})$ and two enclosed arms of the same size with $15-\mathrm{cm}$ high walls. The apparatus was elevated $55 \mathrm{~cm}$ above the floor. Each mouse was placed individually in the central square of the elevated plus-maze apparatus and allowed 5 min for free exploration. Each mouse was observed using the same system as described above for the open field (Ethovision System ${ }^{\circledR}$ software; Noldus Information Technology). The parameters recorded were: a) number of entries into the open and closed arms and b) time spent exploring the open and closed arms. The measures that reflect anxiety levels in this test are the percentage of entries into open arms versus closed arms and the percentage of time spent in the open arms versus closed arms (14).

The animals received vehicle, $0.01,0.1$, or $1.0 \mathrm{mg} / \mathrm{kg}$ anandamide ip in random order ( $N=10 /$ group). Each mouse was tested in the open field and immediately afterwards, mice previously observed in the open field were individually tested for $5 \mathrm{~min}$ in the elevated plus-maze.

Bartlett's test showed that the data obtained were parametric. Thus, they were analyzed by one-way ANOVA (GraphPad InStat version 3.01 for Windows) followed by the Dunnett post hoc test. In all experiments, the probability of $P<0.05$ was taken as an indication of statistical significance. Data are reported as means \pm SEM.

\section{Results}

Anandamide at the dose of $0.1 \mathrm{mg} / \mathrm{kg}$ (but not 0.01 and 
$1 \mathrm{mg} / \mathrm{kg}$ ) increased the distance moved (mean \pm SEM, vehicle: $72.64 \pm 7.6 \mathrm{~cm}$; anandamide $0.01 \mathrm{mg} / \mathrm{kg}: 115.72 \pm$ $11.1 \mathrm{~cm} ; 0.1 \mathrm{mg} / \mathrm{kg}: 166.05 \pm 21.2 \mathrm{~cm} ; 1.0 \mathrm{mg} / \mathrm{kg}: 95.95 \pm$ $8.2 \mathrm{~cm}$ ) and the time spent (mean \pm SEM, vehicle: $3.27 \pm$ $0.8 \mathrm{~s}$; anandamide $0.01 \mathrm{mg} / \mathrm{kg}: 7.49 \pm 1.6 \mathrm{~s} ; 0.1 \mathrm{mg} / \mathrm{kg}$ : $8.30 \pm 1.8 \mathrm{~s} ; 1.0 \mathrm{mg} / \mathrm{kg}: 3.45 \pm 1.0 \mathrm{~s}$ ) in the central zone of the open field $[F(3,36)=9.05, P<0.01 ; F(3,36)=3.66, P<$ 0.05 , respectively). Although a dose of $0.1 \mathrm{mg} / \mathrm{kg}$ is not able to change the locomotion in peripheral zone of the arena, the doses of 0.01 and $1 \mathrm{mg} / \mathrm{kg}$, respectively, increased $(P<0.05)$ and decreased $(P<0.01)$ (mean \pm SEM, vehicle: $992.55 \pm 27.7 \mathrm{~cm}$; anandamide $0.01 \mathrm{mg} / \mathrm{kg}$ : $1100.24 \pm 31.0 \mathrm{~cm} ; 0.1 \mathrm{mg} / \mathrm{kg}: 1045.38 \pm 38.0 \mathrm{~cm} ; 1.0 \mathrm{mg} /$ $\mathrm{kg}: 821.07 \pm 24.6 \mathrm{~cm})$ the locomotion in this zone compared to control $[F(3,36)=15.45]$. Interestingly, no statistical difference in total distance moved or total time spent in movement was observed compared to control, even though the characteristic inverted U-shape pattern was still present (see Figure 1).

Figure $2 A$ and $B$ show the effects of anandamide in the elevated plus-maze. The dose of $0.1 \mathrm{mg} / \mathrm{kg}$ (but not 0.01 and $1 \mathrm{mg} / \mathrm{kg}$ ) increased both the percentage of entries (mean \pm SEM, vehicle: $22.71 \pm 3.3 \%$; anandamide 0.01 $\mathrm{mg} / \mathrm{kg}: 22.90 \pm 2.3 \% ; 0.1 \mathrm{mg} / \mathrm{kg}: 34.76 \pm 3.7 \% ; 1.0 \mathrm{mg} / \mathrm{kg}$ : $23.23 \pm 3.8 \%)[F(3,36)=3.18, P<0.05]$ and the percentage of time spent (mean \pm SEM, vehicle: $2.88 \pm 0.9 \%$; anandamide $0.01 \mathrm{mg} / \mathrm{kg}: 4.43 \pm 1.0 \% ; 0.1 \mathrm{mg} / \mathrm{kg}: 17.70 \pm$ $4.1 \% ; 1.0 \mathrm{mg} / \mathrm{kg}: 6.32 \pm 2.7 \%)$ in the open arms $[F(3,36)=$ $6.88, \mathrm{P}<0.01]$ compared to control. As expected, the contrary was observed in the closed-arms of the apparatus (data not shown). Furthermore, no differences $[F(3,36=$ $1.641, P=0.197$ ] were found in total arm entries (mean \pm SEM, vehicle: $15.2 \pm 1.67$; anandamide $0.01 \mathrm{mg} / \mathrm{kg}: 17.0 \pm$
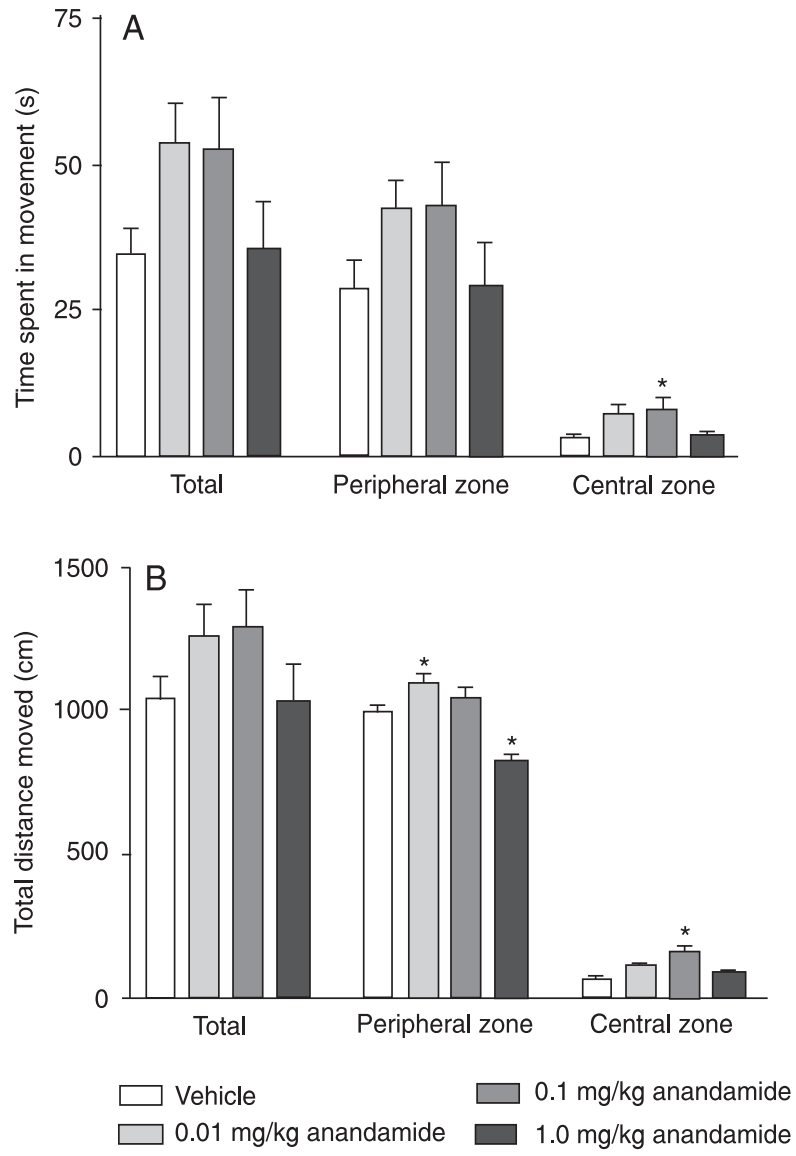

Figure 1. Effects of anandamide on the exploration in the central, peripheral and total area of the open field apparatus. Data are reported as mean \pm SEM for $\mathrm{N}=10$ per group. $A$, Time spent in movement during the $5 \mathrm{~min}$ of the test. $B$, Distance covered during the 5 min of the test. ${ }^{*} P<0.05$ compared to vehicle (oneway ANOVA followed by the Dunnett post hoc test).
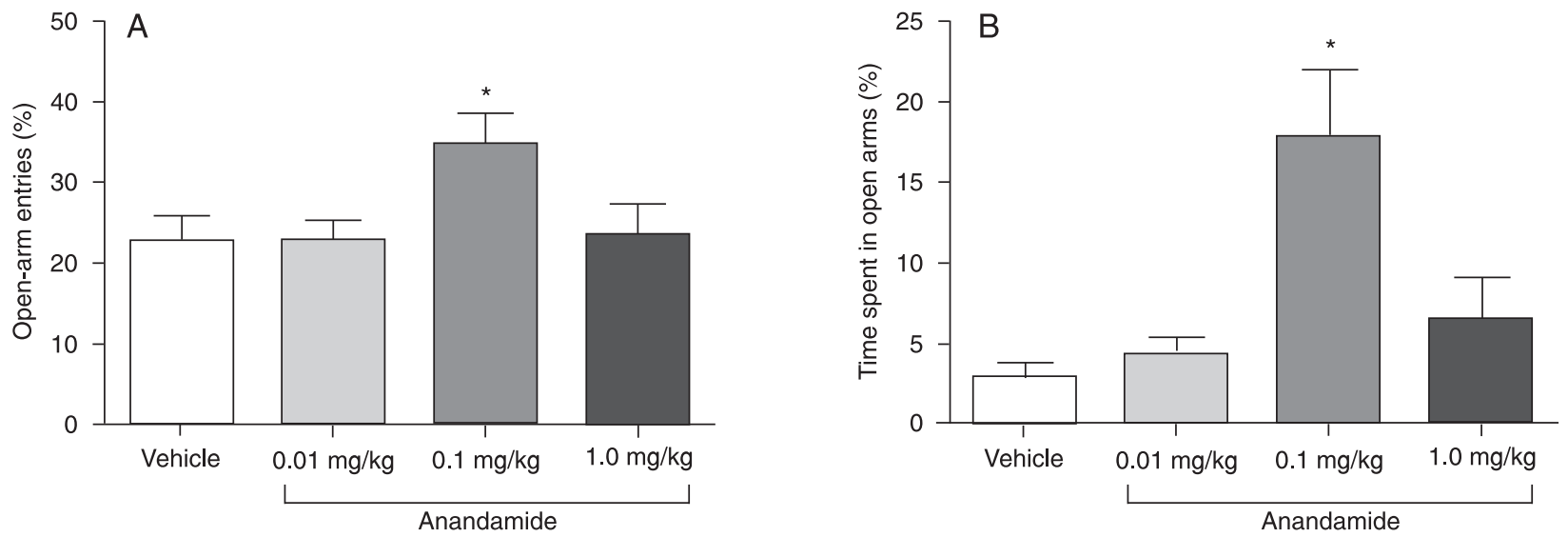

Figure 2. Effects of anandamide in the elevated plus-maze test. Data are reported as mean $\pm \mathrm{SEM}$ for $\mathrm{N}=10$ per group. $A$, Percent entries into the open arms during the 5 min of the test. $B$, Percent time spent in the open arms during the 5 min of the test. ${ }^{*} P<0.05$ compared to vehicle (one-way ANOVA followed by the Dunnett post hoc test). 
$1.67 ; 0.1 \mathrm{mg} / \mathrm{kg}: 19.6 \pm 2.55 ; 1.0 \mathrm{mg} / \mathrm{kg}: 14.3 \pm 1.11)$.

\section{Discussion}

In the present study, we have demonstrated an anxiolytic-like response after the exogenous administration of anandamide at the dose of $0.1 \mathrm{mg} / \mathrm{kg}$ (but not at 0.01 and $1.0 \mathrm{mg} / \mathrm{kg}$ ) in both the open field and elevated plus-maze. In agreement with these data, we observed no change in gait or in the mean velocity in the open field (data not shown) or in the total number of arm entries within the elevated plus-maze (mean \pm SEM described above), facts that strongly suggest the presence of normal locomotor activity. We observed that treatment with $0.1 \mathrm{mg} / \mathrm{kg}$ anandamide led to an increase in exploration mainly in the open field central zone. This particular behavior might be an indication of an anxiolytic-like effect induced by anandamide, since it is known that rodents present a conflict between their natural curiosity to explore novel areas versus an aversion of open areas when first exposed to them $(15,16)$. The data obtained in the elevated plus-maze agree with the anxiolytic-like effect induced by anandamide $(0.1 \mathrm{mg} / \mathrm{kg})$ in the open field. We observed an increase in both percent time spent and the percent entries into the open arms. Both the increased percentage of entries and of time spent exploring the open arms together with the absence of changes in the total number of arm entries are considered to be good indicators of anxiolyticlike effects in this model (17). Therefore, our data corroborate with some recent reports that have shown the anxiolytic-like effects of anandamide in different models of anxiety, such as the Vogel conflict test (18), elevated plusmaze (19), and light/dark box test (20). Furthermore, some reports have shown the same anxiolytic-like properties of compounds that alter endocannabinoid signaling, such as AM404 (an anandamide transport inhibitor) (8) and URB597 (an inhibitor of anandamide hydrolysis) (9).

Additionally, in the present study, a characteristic inverted U-shaped dose-response curve for anandamide was observed in both the open field and elevated plusmaze. Other studies have shown the anxiolytic-like effect induced by anandamide with a characteristic inverted Ushaped pattern curve after its administration, in addition to other compounds that alter endocannabinoid signaling in rodents (8-11). Using a dose-response protocol, Moreira et al. (8) showed that intra-dorsolateral periaqueductal injection of anandamide produced an inverted $U$-shape curve and an anxiolytic-like effect in the elevated plusmaze (8). More recently Scherma et al. (20) showed that anandamide systemically injected produced an anxiolyticlike effect in the light/dark box test at a dose $(0.3 \mathrm{mg} / \mathrm{kg})$ closely similar to that used in our study.

This characteristic inverted U-shape pattern is the result of the biphasic effects observed after low and high doses of (endo)cannabinoids. Low doses are reported to be anxiolytic, whereas high doses are reported to be anxiogenic (5). In the past, it was difficult to explain these findings; however, it has been recently proposed that the opposite effects produced by low and high doses of these compounds might be due to their ability to interact with different receptors (6). Recently, Rubino et al. (19) demonstrated that the anxiolytic-like effect of a low anandamide dose was reversed by administration of the specific CB1 receptor antagonist $A M 251$, whereas the anxiogenic-like effect was inhibited by pretreatment with capsazepine, a TRPV1 (transient receptor potential vanilloid type 1) receptor antagonist. The authors suggested that the anxiolytic effect evoked by anandamide might be due to the interaction with the CB1 cannabinoid receptor, whereas vanilloid receptors seem to be involved in the anxiogenic action of anandamide (19). Therefore, the anandamideinduced inverted $U$-shape pattern might be based on the fact that the intrinsic efficacy of anandamide on TRPV1 is relatively low compared to that observed on the CB1 receptor (6).

Moreover, a recent report by Bitencourt et al. (12) showed an anxiolytic-like effect of AM404 and cannabidiol in a model of fear-potentiated elevated plus-maze. This study suggests that these compounds exert distinct effects depending on the emotional state of the individual, thus representing an original class of anxiolytic drugs. This hypothesis is supported by the observation of oscillations in endocannabinoid tonus during stressful situations (12). Interestingly, in our work, mice were tested in the elevated plus-maze immediately after the stress of being placed in the open field arena. Although the behavioral outcomes of anandamide in the open field were not very different, in the elevated plus-maze the effect of $0.1 \mathrm{mg} / \mathrm{kg}$ was exceedingly evident. Differences in animal response to fear of novelty (open field) versus fear of open and elevated areas (elevated plus-maze) might account for the more prominent effect of anandamide in the latter apparatus. Indeed, the elevated plus-maze is known to be more stressful than the open field (15). These assumptions agree with this recent reported data (12).

This research showed for the first time a dose-response effect for the anxiolytic-like effects of anandamide injected systemically. Moreover, our results corroborated recent data (12) that showed the relevance of the emotional state of the individual for the anxiolytic-like effects of the (endo)cannabinoids, such as anandamide. 


\section{References}

1. Matsuda LA, Lolait SJ, Brownstein MJ, Young AC, Bonner TI. Structure of a cannabinoid receptor and functional expression of the cloned cDNA. Nature 1990; 346: 561-564.

2. Devane WA, Hanus L, Breuer A, Pertwee RG, Stevenson LA, Griffin G, et al. Isolation and structure of a brain constituent that binds to the cannabinoid receptor. Science 1992; 258: 1946-1949.

3. Munro S, Thomas KL, Abu-Shaar M. Molecular characterization of a peripheral receptor for cannabinoids. Nature 1993; 365: 61-65.

4. Mechoulam R, Ben-Shabat S, Hanus L, Ligumsky M, Kaminski NE, Schatz AR, et al. Identification of an endogenous 2-monoglyceride, present in canine gut, that binds to cannabinoid receptors. Biochem Pharmacol 1995; 50: 8390.

5. Viveros MP, Marco EM, File SE. Endocannabinoid system and stress and anxiety responses. Pharmacol Biochem Behav 2005; 81: 331-342.

6. Ross RA. Anandamide and vanilloid TRPV1 receptors. Br J Pharmacol 2003; 140: 790-801.

7. Sulcova E, Mechoulam R, Fride E. Biphasic effects of anandamide. Pharmacol Biochem Behav 1998; 59: 347352.

8. Moreira FA, Aguiar DC, Guimaraes FS. Anxiolytic-like effect of cannabinoids injected into the rat dorsolateral periaqueductal gray. Neuropharmacology 2007; 52: 958-965.

9. Kathuria S, Gaetani S, Fegley D, Valino F, Duranti A, Tontini $A$, et al. Modulation of anxiety through blockade of anandamide hydrolysis. Nat Med 2003; 9: 76-81.

10. Moreira FA, Kaiser N, Monory K, Lutz B. Reduced anxietylike behaviour induced by genetic and pharmacological inhibition of the endocannabinoid-degrading enzyme fatty acid amide hydrolase (FAAH) is mediated by CB1 receptors. Neuropharmacology 2008; 54: 141-150.

11. Bortolato $M$, Campolongo $P$, Mangieri RA, Scattoni $M L$, Frau R, Trezza V, et al. Anxiolytic-like properties of the anandamide transport inhibitor AM404. Neuropsychopharmacology 2006; 31: 2652-2659.

12. Bitencourt RM, Pamplona FA, Takahashi RN. Facilitation of contextual fear memory extinction and anti-anxiogenic effects of AM404 and cannabidiol in conditioned rats. Eur Neuropsychopharmacol 2008; 18: 849-859.

13. Palermo-Neto J, Guimaraes RK. Pavlovian conditioning of lung anaphylactic response in rats. Life Sci 2000; 68: 611623.

14. Pellow S, Chopin P, File SE, Briley M. Validation of open: closed arm entries in an elevated plus-maze as a measure of anxiety in the rat. $J$ Neurosci Methods 1985; 14: 149-167.

15. Commissaris RL. Conflict behaviors as animal models for the study of anxiety. In: Van Haaren F (Editor), Methods in behavioral pharmacology. Amsterdam: Elsevier; 1993. p 443-466.

16. Prut $L$, Belzung $C$. The open field as a paradigm to measure the effects of drugs on anxiety-like behaviors: a review. Eur J Pharmacol 2003; 463: 3-33.

17. Lister RG. The use of a plus-maze to measure anxiety in the mouse. Psychopharmacology 1987; 92: 180-185.

18. Lisboa SF, Resstel LB, Aguiar DC, Guimaraes FS. Activation of cannabinoid $\mathrm{CB} 1$ receptors in the dorsolateral periaqueductal gray induces anxiolytic effects in rats submitted to the Vogel conflict test. Eur J Pharmacol 2008; 593: 7378.

19. Rubino T, Realini N, Castiglioni C, Guidali C, Vigano D, Marras E, et al. Role in anxiety behavior of the endocannabinoid system in the prefrontal cortex. Cereb Cortex 2008; 18: $1292-1301$.

20. Scherma M, Medalie J, Fratta W, Vadivel SK, Makriyannis A, Piomelli $D$, et al. The endogenous cannabinoid anandamide has effects on motivation and anxiety that are revealed by fatty acid amide hydrolase (FAAH) inhibition. Neuropharmacology 2008; 54: 129-140. 